\title{
Characteristics of Natural Background Radiation in the Polkowice-Sieroszowice Mine, Poland
}

\author{
Katarzyna Szkliniarz 1,*D , Agata Walencik-Łata ${ }^{1} \mathbb{D}$, Jan Kisiel ${ }^{1,2}$, Kinga Polaczek-Grelik ${ }^{3}$, Karol Jędrzejczak ${ }^{4} \mathbb{D}$, \\ Marcin Kasztelan ${ }^{4}$ (D) Jacek Szabelski ${ }^{4}$ (D), Jerzy Orzechowski ${ }^{4}$, Przemysław Tokarski ${ }^{4}$, Włodzimierz Marszał ${ }^{4}$, \\ Marika Przybylak ${ }^{4}$, Krzysztof Fuławka ${ }^{5}$ and Sebastian Gola ${ }^{6,7}$ (D)
}

check for updates

Citation: Szkliniarz, K.; Walencik-Łata, A.; Kisiel, J.; Polaczek-Grelik, K.; Jędrzejczak, K.; Kasztelan, M.; Szabelski, J.;

Orzechowski, J.; Tokarski, P.;

Marszał, W.; et al. Characteristics of Natural Background Radiation in the Polkowice-Sieroszowice Mine,

Poland. Energies 2021, 14, 4261.

https://doi.org/10.3390/en14144261

Academic Editor: Agnieszka Iwan

Received: 27 June 2021

Accepted: 11 July 2021

Published: 14 July 2021

Publisher's Note: MDPI stays neutral with regard to jurisdictional claims in published maps and institutional affiliations.

Copyright: (c) 2021 by the authors. Licensee MDPI, Basel, Switzerland This article is an open access article distributed under the terms and conditions of the Creative Commons Attribution (CC BY) license (https:// creativecommons.org/licenses/by/ $4.0 /)$
1 August Chełkowski Institute of Physics, University of Silesia in Katowice, 75 Pułku Piechoty 1, 41-500 Chorzów, Poland; agata.walencik@us.edu.pl (A.W.-Ł.); jan.kisiel@us.edu.pl (J.K.)

2 The Henryk Niewodniczański Institute of Nuclear Physics Polish Academy of Sciences, Walerego Eljasza Radzikowskiego 152, 31-342 Kraków, Poland

3 NU-Med Cancer Diagnosis and Treatment Centre Katowice, Ceglana 35, 40-514 Katowice, Poland; kinga.grelik@gmail.com

4 National Centre for Nuclear Research, 28 Pułku Strzelców Kaniowskich 69, 90-558 Łódź, Poland; karol.jedrzejczak@ncbj.gov.pl (K.J.); marcin.kasztelan@ncbj.gov.pl (M.K.); jacek.szabelski@ncbj.gov.pl (J.S.); jerzy.orzechowski@ncbj.gov.pl (J.O.); przemyslaw.tokarski@ncbj.gov.pl (P.T.); wlodzimierz.marszal@ncbj.gov.pl (W.M.); marika.przybylak@ncbj.gov.pl (M.P.)

5 KGHM CUPRUM Research \& Development Centre, Sikorskiego 2-8, 53-659 Wrocław, Poland; kfulawka@cuprum.wroc.pl

6 Faculty of Geoengineering, Mining and Geology, Wrocław University of Science and Technology, Na Grobli 15, 50-421 Wrocław, Poland; sebastian.gola@pwr.edu.pl

7 KGHM Polska Miedź S.A. O/ZG Polkowice-Sieroszowice, Kaźmierzów 100, 59-101 Polkowice, Poland

* Correspondence: katarzyna.szkliniarz@us.edu.pl; Tel.: +48-32-3497751

Abstract: Natural radioactivity in underground locations is the main parameter for the safety of work (occupational hazards) and for the success of experiments in physics or biology requiring unique conditions. The characterization of natural prominence was carried out in the Conceptual Lab development in one of KGHM deep copper mines co-ordinated by KGHM Cuprum R\&D. Natural radioactivity studies were performed and included in situ gamma spectrometry, neutron flux measurements, radon concentration, and alpha and gamma laboratory spectrometry measurements of rock samples. At a depth of $1014.4 \mathrm{~m}$ (2941.8 m w.e.) within the anhydrite layer, a neutron flux of $2.0 \pm 0.2 \times 10^{-6} \mathrm{~cm}^{-2} \mathrm{~s}^{-1}$, a gamma-ray dose of $0.008 \pm 0.001 \mu \mathrm{Sv} / \mathrm{h}$, a photon flux density of $0.64 \pm 0.20 \mathrm{~cm}^{-2} \mathrm{~s}^{-1}$, and a radon concentration of $6.6 \mathrm{~Bq} / \mathrm{m}^{3}$ were determined. Laboratory analyses of ${ }^{226,228} \mathrm{Ra},{ }^{40} \mathrm{~K}$, and ${ }^{238,234} \mathrm{U}$ concentrations in collected rock samples showed low values. The exceptionally low level of natural radioactivity in the Polkowice-Sieroszowice mine makes this location a unique place for scientific research.

Keywords: natural radiation; underground laboratory; radioisotopes concentration

\section{Introduction}

Natural radioactivity surrounds us everywhere. It originates from cosmic radiation, radionuclides created during the interaction of cosmic radiation with components of the atmosphere and radionuclides present in the earth's crust. However, some places such as underground sites show a low level of natural radioactivity, making them an excellent place for specific research in the field of physics, astrophysics (search for dark matter, double beta decay), biology, environmental science, and other fields [1-4]. Therefore, it is essential to characterize these locations in terms of natural radioactivity and their sources of origin. In underground locations, natural radioactivity mainly comes from the cosmic ray muon flux (created when protons and secondary particles interact with atoms in the atmosphere), the decay of radionuclides belonging to the decay chains of uranium and thorium $\left({ }^{238} \mathrm{U},{ }^{232} \mathrm{Th}\right)$ and single very long-lived radionuclides $\left({ }^{40} \mathrm{~K}\right)$, the 
spontaneous fission of $U$ and Th, and the interaction of neutrons that derive from $(\alpha, n)$ reactions. The level of natural radioactivity in underground locations depends on the depth of the underground laboratory, the local geology, and the materials used to strengthen the structures of underground rooms (including concrete). Measurements of the natural radiation background are, on the one hand, crucial to ensure safe work in underground locations, and, on the other hand, they allow areas in mines to be identified that are suitable for possible transformation of mining excavations for the needs of, e.g., physical sciences.

The study of natural radioactivity was carried out at the place which is considered to be one of the potentially suitable places for an Underground Laboratory in the future, the Polkowice-Sieroszowice mine, Poland. This facility was one of the testing sites (ULs) participating in the BSUIN (Baltic Sea Underground Innovation Network) and EUL (Empowering Underground Laboratories Network Usage) and is co-ordinated by the KGHM Cuprum R\&D center. The mine is one of the largest active underground copper mines in the world. The mine's infrastructure is very well developed and at the moment, there are hundreds of kilometers of workings, which are easily accessible. Still, there are no typical underground facilities or research panels within the excavated area, which could be used for the purposes of science, research and development of tourism. Therefore, conducting detailed measurements of the level of natural radioactivity in these locations is necessary to determine the radiation hazard and the possibility of conducting various experiments requiring unique conditions.

Earlier studies of natural radioactivity in the Polkowice-Sieroszowice mine were carried out in the salt bed in the P1 chamber at a depth of $930 \mathrm{~m}[5,6]$. The studies showed a very low level of natural radioactivity. The average dose rate was $1.8 \mathrm{nGy} / \mathrm{h} \mathrm{[5]}$, and gamma-ray flux of $0.124 \pm 0.002 \mathrm{~cm}^{-2} \mathrm{~s}^{-1}$ [6]. Moreover, the determined values of Th and $\mathrm{U}$ concentrations in the collected salt samples were much lower (below $1 \mathrm{~Bq} / \mathrm{kg}$ ) than for a typical rock (about 20-30 Bq/ kg) [5,7].

Due to inter alia, very stable tectonic conditions, and a very low level of natural background radiation, the mine was one of the primary candidates for the location of the underground SUNLAB laboratory-two laboratories SUNLAB1 (a small laboratory) located in a salt layer, and SUNLAB2 (a large laboratory) located in anhydrite [8,9]—to host the European project LAGUNA FP7 [10] with a 100 kton GLACIER liquid argon detector for physics research.

As a result of the mine's development plans, the P1 salt chamber was no longer considered. Therefore, the natural radioactivity was measured in a different location near the SW-1 shaft. The research included in situ gamma-ray spectrometry measurements, measurements of thermal neutron flux and radon concentration in the air, as well as laboratory analysis of radium $\left({ }^{226,228} \mathrm{Ra}\right)$, uranium $\left({ }^{234,238} \mathrm{U}\right)$, and potassium $\left({ }^{40} \mathrm{~K}\right)$ radioisotope concentration in the collected rock samples using alpha and gamma spectrometry.

\section{Site Geology}

Continuous radiation measurement was conducted in the Polkowice-Sieroszowice underground copper mine, which is located to the northwest of the Polkowice city in the Lower Silesia Voivodeship. The measuring site was located in direct vicinity to the SW-1 shaft at a depth of $1014.4 \mathrm{~m}$ (2941.8 $\mathrm{m}$ w.e.) below the ground surface which corresponds to $786 \mathrm{~m}$ below sea level. The copper deposit in the research area is classified as stratoidal and single-level. The mining activities near the SW-1 shaft have proceeded within Light grey anhydrite strata. The roof of the analysed area consists of a high strength anhydrite layer with a thickness of $114.4 \mathrm{~m}$. Over it, the rock salt strata and anhydrite with clays with a total thickness of about $200 \mathrm{~m}$ are located. The anhydrite and clay strata are covered by $270 \mathrm{~m}$ of sandstone layers. Above it, there are tertiary formations in the form of clays and quartz sands as well as quaternary sands and clay with a total thickness of about $430 \mathrm{~m}$. In turn, on the floor of the measuring site, a thin layer of light grey anhydrite is located. Below it, there are weak layers of white and red quartz sandstone. The geologic profile of the analyzed region is presented in Figure 1. 


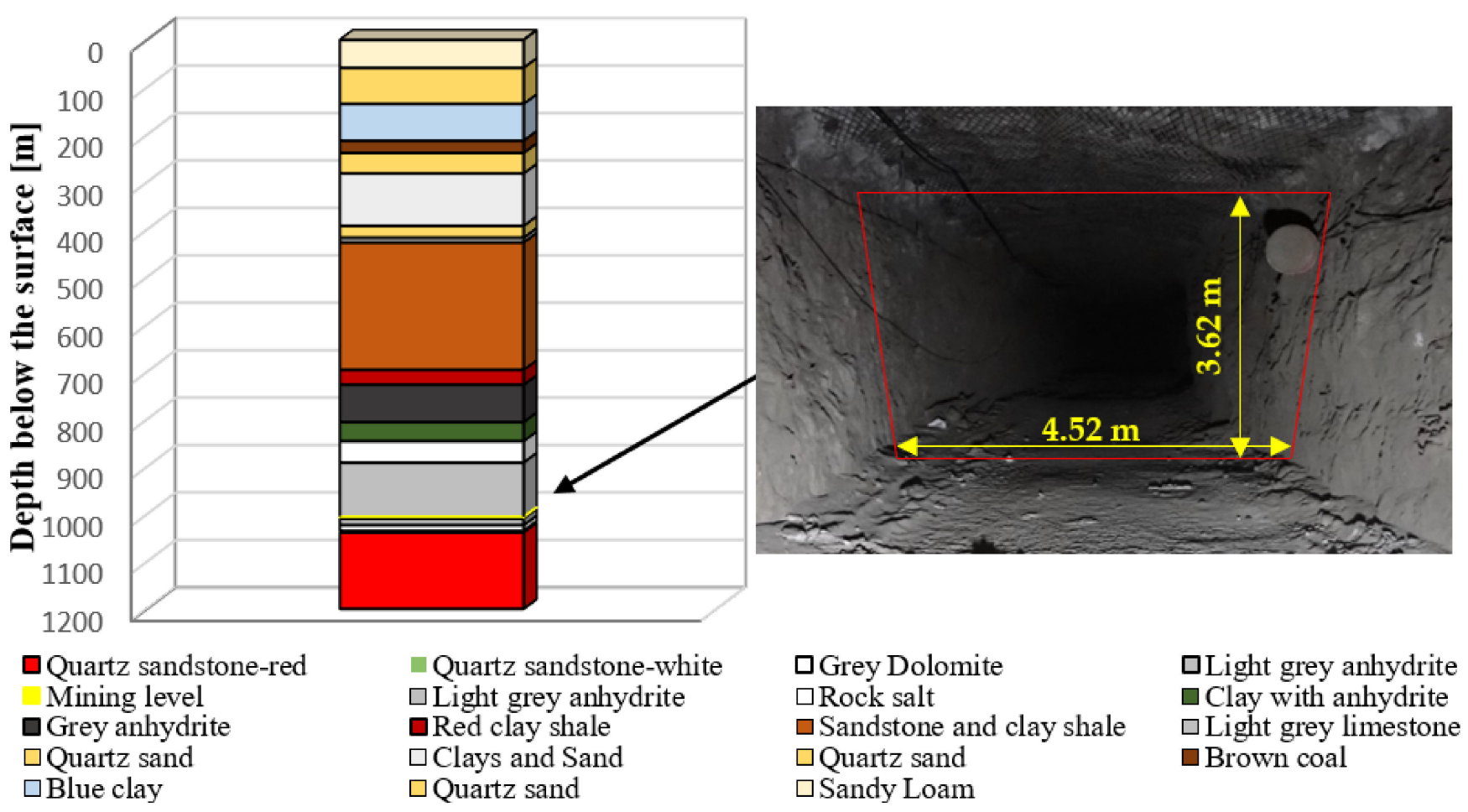

Figure 1. Geologic profile of analyzed mining region.

The cross-section of the gallery is about $16.4 \mathrm{~m}^{2}$. At the same time, its shape may be characterized as rectangular. Concerning the environmental conditions, the temperature and humidity in the surrounding measuring site were moderate. The dry-bulb temperature during the measurements was on average $25.6{ }^{\circ} \mathrm{C}$, while the wet-bulb temperature was equal to $18.8^{\circ} \mathrm{C}$. The overall humidity was $52 \%$.

\section{Materials and Methods}

In situ gamma measurements were performed in excavation No. 3 in the vicinity of the SW-1 shaft (at a depth of $1014.4 \mathrm{~m}$ ). Detectors were installed side by side at $85 \mathrm{~m}$ excavation No 3, $3.62 \mathrm{~m}$ high and $4.52 \mathrm{~m}$ wide, covered with anhydrite (Figure 1). In situ measurements were performed using a high-purity germanium (HPGe) semiconductor spectrometer, an RAD7 electronic radon detector (Durridge Company, Inc.), and neutron helium proportional counters (Figure 2). Additionally, seven rock samples were collected from the investigated location for more detailed natural radioactivity measurements. These measurements were performed in the August Chełkowski Institute of Physics, University of Silesia in Katowice, using alpha and gamma spectrometry techniques. Rock samples for laboratory analysis were collected directly from the walls of various parts of the mining gallery, where in situ measurements were carried out. 


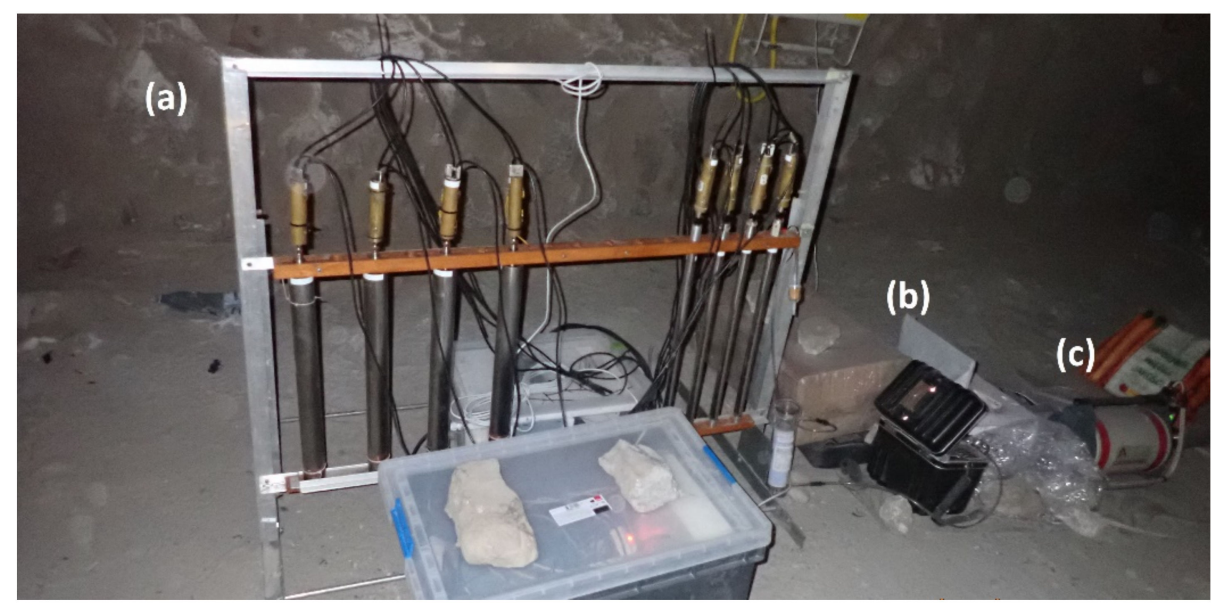

Figure 2. Measurement setup used during the measurements: (a) visible flat tray of helium counters placed vertically in the stand; visible Centronic (thicker) and ZDAJ (thinner) counters (at the base of the tray, as well as plastic boxes which are dustproof housing for DAQ (background one) and power suppliers (foreground one)); (b) radon monitor RAD7; (c) HPGe spectrometer.

\subsection{In Situ Gamma Spectrometry}

A portable spectrometer setup (Canberra Industries, Inc., Meriden, CT, USA) consisting of a high-purity germanium detector with reverse electrodes (REGe) and a $0.6 \mathrm{~mm}$ thick carbon-composite entrance window connected via a multichannel analyser InSpector 2000 to a PC software Gennie ${ }^{\mathrm{TM}} 2000$ v.3.2.1, was used for in situ acquisition of gamma-ray spectra. The detector's active volume was placed about $30 \mathrm{~cm}$ above the ground and about $2.2 \mathrm{~m}$ away from the side walls. The detector is liquid nitrogen cooled, has $40 \%$ nominal efficiency, $2.1 \mathrm{keV}$ FWHM at $1.33 \mathrm{MeV}{ }^{60} \mathrm{Co}$ line, and a peak-to-Compton ratio of $57 / 1$. The measuring energy was established in the range $10-3100 \mathrm{keV}$ using a spectrometric gain of 2.5 .

Registered spectra were analyzed using Gennie ${ }^{\mathrm{TM}} 2000$ v.3.2.1 software in terms of radioisotopes identification based on peak energy and peak area determination. Energy calibration was conducted based on a well-known natural background radiation spectrum measured in laboratory conditions, which was assumed to be qualitatively similar to the one at the experimental site. The area under each peak of the spectrum was determined using the automated sequence of analysis involving unidentified second differential and non-linear LSQ fit available in Genie ${ }^{\mathrm{TM}} 2000$ software. Each peak area result was reported with a relative uncertainty.

A spectrum registered in situ conditions enables the assessment of several quantities descriptive for the radiation hazard at the measurement point and its vicinity, provided that the proper calibrations and characterizations are accessible for the special equipment as well as for the measurement site.

The estimation of gamma-ray flux, apparent radioactivity (as seen by on-site detector, in contrast to laboratory radiochemical analysis of activity concentration in rock samples), or effective dose rate at a measurement point requires detection efficiency calibration. This is usually done experimentally when the experimental geometry can be recreated in laboratory conditions using calibration sources or computationally using efficiency modeling in dedicated software that uses detector characterization (established using Monte Carlo simulations) delivered by the manufacturer.

In the presented study, the efficiency curve for the HPGe detector was obtained in ISOCS ${ }^{\mathrm{TM}}$ software (Canberra Inc., Meriden, CT, USA) using geometry modeled in Geometry Composer software (Canberra Industries, Inc., Meriden, CT, USA). For the horizontal orientation of a spectrometer, the geometry for efficiency calibration was based on room/box with internal surface contamination (the best match for measurement geometry from the templates provided by the software producer) with dimensions of excavation No. 
3. Radioactivity was assumed to be distributed equally between 5 out of the 6 walls (the back wall was excluded as having a negligible contribution to the registered spectra).

The gamma-ray detection efficiency $(\varepsilon)$ was described as a function of photon energy (E) by the polynomial of the fifth-degree with Equation (1), which enables the calculation of the specific efficiency for gamma lines observed at the registered spectrum.

$$
\ln (\varepsilon)=-5.611-16.68 \ln (E)+9.283 \ln (E)^{2}-2.094 \ln (E)^{3}+0.2104 \ln (E)^{4}-0.0079 \ln (E)^{5} .
$$

The gamma-ray flux density $(\Phi)$ at the measuring point was determined according to Equation (2), taking into account the net area of each gamma line peaked at energy E on the registered spectrum, the detection efficiency $(\varepsilon)$, the area of detector surface $\left(\mathrm{S}_{\mathrm{Ge}}\right)$ and the live time (LT) of measurement.

$$
\Phi(\mathrm{E})\left[\mathrm{cm}^{-2} \mathrm{~s}^{-1}\right]=\frac{\text { peak_net_area }(\mathrm{E})}{\varepsilon(\mathrm{E}) \mathrm{S}_{\mathrm{Ge}}\left[\mathrm{cm}^{2}\right] \mathrm{LT}[\mathrm{s}]} .
$$

The uncertainty of flux density accounted for the uncertainties of the peak net area and $10 \%$ accuracy of the modeled efficiency, treated as independent variables.

Based on photon flux density and taking into account the quantum efficiencies of gamma ray emission by each identified radionuclide, the apparent activity of rocks as seen by the in situ spectrometer was assessed. For each radionuclide that emits photons of more than one energy, the activity was calculated as an average over the activities determined based on the particular peaks. In this case, the uncertainty was determined as the standard deviation.

Subsequently, using photon flux-to-dose conversion coefficients, an effective dose inside excavation No. 3 (at the point of spectrometer location) was estimated. ICRP conversion coefficients [11] for isotropic geometry of irradiation were used, interpolated with the third-degree Lagrange formula for photon energies recognized at the registered spectrum. The uncertainty of effective dose rate took into account the uncertainties of photon flux density and 10\% accuracy of ICRP conversion coefficients, treated as independent variables.

\subsection{In Situ Radon Measurement in Air}

${ }^{222} \mathrm{Rn}$ concentration was measured using a RAD7 portable detector (Durridge Company, Inc.). The detector was placed next to the gamma spectrometer at the center of the shaft (Figure 2b,c). The radon concentration in air was measured using a 2-day protocol with a 1-h measurement cycle. Analysis of radon was based on an electrostatic collection of alpha-emitters with spectral analysis using a semiconductor alpha detector with 5\% absolute accuracy and intrinsic background of $0.005 \mathrm{pCi} / \mathrm{L}\left(0.2 \mathrm{~Bq} / \mathrm{m}^{3}\right)$. This spectrometer enables ${ }^{222} \mathrm{Rn}$ concentration to be measured based on the installed pre-programmed setups.

\section{3. $\alpha$-and $\gamma$-Laboratory Spectrometry Techniques}

Rock samples were taken from different parts of the gallery so that it was possible to estimate the homogeneity of the radionuclide distribution. The measurements of the concentrations of ${ }^{40} \mathrm{~K},{ }^{226} \mathrm{Ra}$, and ${ }^{228} \mathrm{Ra}\left({ }^{228} \mathrm{Ac}\right)$ isotopes in the collected rock samples were performed using a low-background laboratory gamma spectrometry technique. Before the measurements, samples were adequately prepared. Rock samples were dried, crushed, ground, and placed in Marinelli beakers. Beakers then were sealed and stored for a month to allow for secular equilibrium in the thorium and uranium series. Then, the samples were measured for about 3 to 10 days, depending on the activity. The measurements of ${ }^{40} \mathrm{~K},{ }^{226} \mathrm{Ra}$, and ${ }^{228} \mathrm{Ra}$ concentrations were performed using a gamma spectrometer (Mirion Technologies (Canberra), Inc., Meriden, CT, USA). This spectrometer consists of high purity germanium (HPGe) detector model: GC2018 of $60.7 \mathrm{~mm}$ crystal diameter and a Cryo-Pulse 5 Plus an electrically-powered cryostat (Mirion Technologies (Canberra), Inc., Meriden, CT, USA). The detector is shielded with $11 \mathrm{~cm}$ low-background lead from Ortec. The HPGe detector has a relative efficiency of $20 \%$, energy resolution FWHM of $1.8 \mathrm{keV}$, and a P/C 
ratio of $50: 1$ at a $1.33 \mathrm{MeV}^{60} \mathrm{Co}$ gamma line. The energy calibration and radioactivity concentrations were calculated based on a standard prepared from the certified materials obtained from the Central Laboratory for Radiological Protection in Poland. The acquisition and analysis of the spectra were performed with the use of Genie 2000 ${ }^{\mathrm{TM}}$ software v.3.4.1.

The concentration of ${ }^{40} \mathrm{~K}$ isotope in rock samples was calculated based on the $1460.8 \mathrm{keV}$ gamma line. The concentration of ${ }^{228} \mathrm{Ra}$ was calculated based on the $911.1 \mathrm{keV}$ gamma line originating from ${ }^{228} \mathrm{Ac}$. The ${ }^{226} \mathrm{Ra}$ concentration in collected samples was calculated as the weighted mean of the activities of ${ }^{214} \mathrm{~Pb}(295.2,351.9 \mathrm{keV})$ and ${ }^{214} \mathrm{Bi}(609.3,1120.3 \mathrm{keV})$.

The uncertainty of the final activities, especially for low radioactive samples, reached a value of $20 \%$. For each analyzed isotope, the corresponding uncertainty was calculated as the square root of the sum of uncertainties in all quantities in the quadrate. The uncertainty of the weighted mean of ${ }^{226} \mathrm{Ra}$ isotope was calculated as the reciprocal square root of the sum of all individual weights.

All samples were also analyzed for the presence of uranium radioisotopes $\left({ }^{234,238} \mathrm{U}\right)$. For this purpose, sub-samples weighing about 1-2 g were prepared for alpha spectrometry measurements. Before the measurements, rock samples were digested in a PTFE pressure decomposition vessel using a microwave unit MAGNUM II (ERTEC, Poland). In order to calculate the ${ }^{234,238} \mathrm{U}$ concentrations and determine the chemical efficiency, a ${ }^{232} \mathrm{U}$ isotope was added to each sample. The wet-mineralization of the collected rock samples was performed using hot acids: $\mathrm{HF}, \mathrm{HNO}_{3}, \mathrm{HCl}$ with $\mathrm{H}_{3} \mathrm{BO}_{3}$. Then, uranium was pre-concentrated with iron and co-precipitated with ammonia at $\mathrm{pH}$ 9. Uranium was separated from other alpha emitters using the anion exchange resin Dowex $1 \times 8$ ( $\mathrm{Cl}^{-}$-type, 200-400 mesh). Then, a thin $\alpha$ spectrometry source was prepared from the uranium fraction by coprecipitation with $\mathrm{NdF}_{3}$ and filtration. The measurements of ${ }^{234,238} \mathrm{U}$ concentrations were performed with the use of 7401VR (Canberra-Packard) and Alpha Analyst $^{\mathrm{TM}}$ (Mirion Technologies (Canberra), Inc., USA) alpha spectrometers equipped with passivated implanted planar silicon (PIPS) detectors. The minimum detectable activity (MDA) was equal to $0.4 \mathrm{mBq} / \mathrm{L}$ for both ${ }^{234,238} \mathrm{U}$ isotopes and measurement lasted two days. The spike sample was prepared based on distilled water of a volume of $0.5 \mathrm{~L}$.

\subsection{Neutron Flux Measurements}

The neutron background measurements were made using helium counters, i.e., gas proportional counters filled with helium-3 $\left({ }^{3} \mathrm{He}\right)$. In this type of detector, neutrons are captured by the helium nucleus in the reaction (3) and the charged products (proton and tritium) of the reaction appear with kinetic energy of $764 \mathrm{keV}$. These products ionize so that they can be detected by a proportional counter like standard radiation. This method is sensitive only for thermal neutrons (energy $\sim 0.02 \mathrm{eV}$ ). As the energy of these neutrons is negligible compared to the heat of the reaction $(764 \mathrm{keV})$, neutron registrations form a very characteristic "peak and tail" amplitude spectrum. This allows neutron events to be distinguished even with a large background of other types of radiation.

$$
{ }^{3} \mathrm{He}(\mathrm{n}, \mathrm{p})^{3} \mathrm{H}+764 \mathrm{keV} .
$$

The determination of the neutron flux requires the use of the Monte Carlo simulation. The simulations were carried out using the Geant4 package version 10.07 using the physical package QGSP_BERT_HP and NeutronHPThermalScattering, which is essential for lowenergy neutron interactions with nucleons bound in nuclei. In this simulation, the helium counter tray model was placed in the center of an empty sphere with a diameter of $3 \mathrm{~m}$. Each point at the sphere surface was an isotropic source of thermal neutrons. We evaluated the expected count probability per emitted neutron by each detector. There is an analytical formula for the evaluation of the isotropic neutron flux in the center of the sphere as a function of emitted neutron rate and sphere radius. Then, the ratio of the simulated counters counting rate to the simulated neutron flux was determined. Knowing this ratio and the measured counting rate one can determine the neutron flux at the measurement site. 


\section{Results and Discussion}

\subsection{Analysis of the Gamma-ray Spectrum}

The gamma-ray spectrum registered in situ for $24 \mathrm{~h}$ inside excavation No. 3 near the SW-1 shaft of the Polkowice-Sieroszowice copper mine is shown in Figure 3. The spectrum presented in terms of count rate normalized to the day, energy $(\mathrm{keV})$, and mass of germanium crystal $\left(\mathrm{kg}_{\mathrm{Ge}}\right)$ allows comparison the level of radioactivity with other underground locations. The comparison of the counts' rate $\left[\mathrm{s}^{-1}\right]$ in various underground laboratories is presented in Table 1 .

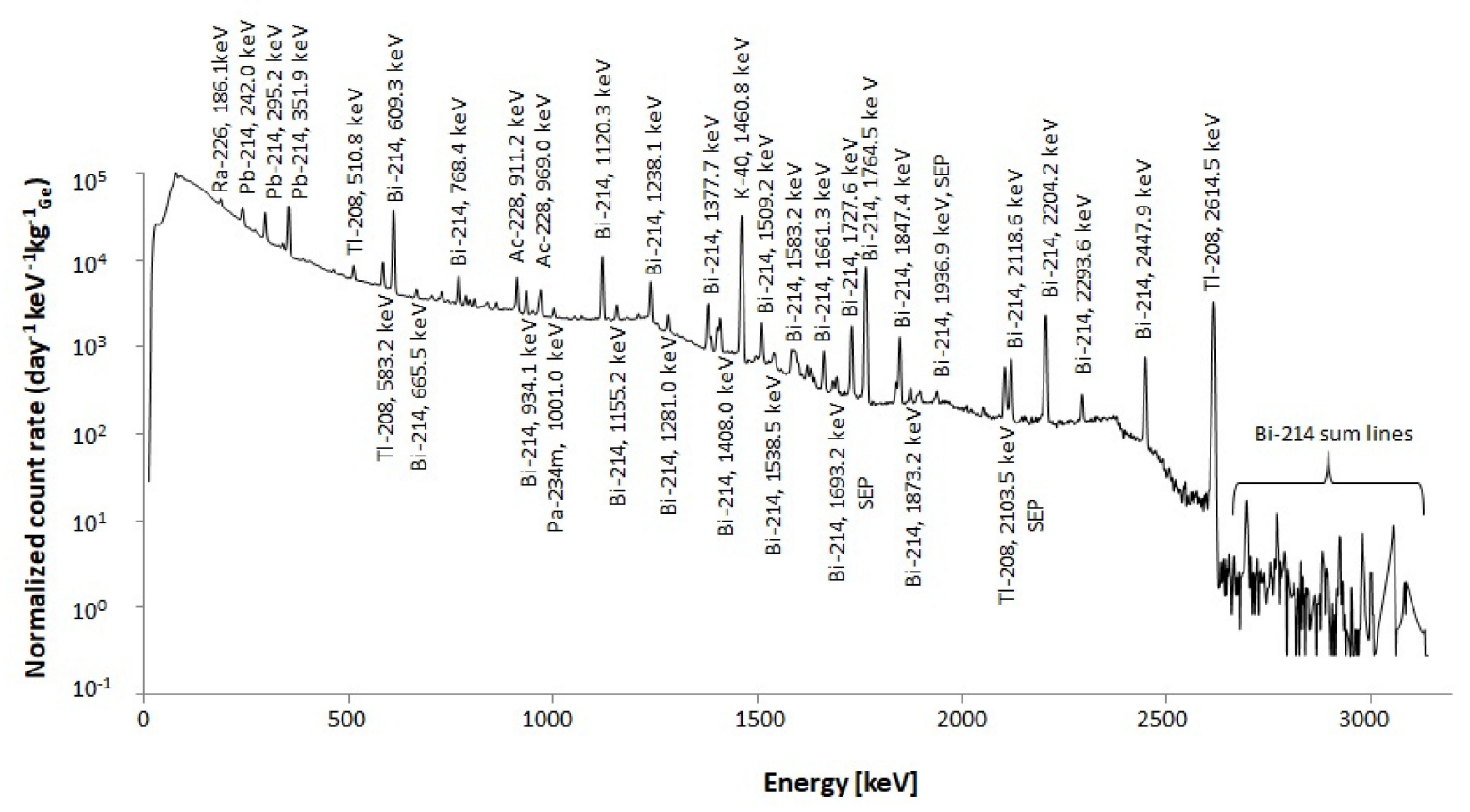

Figure 3. Gamma ray spectrum registered in situ in excavation No. 3 near SW-1 shaft. The main visible peaks are identified.

Table 1. Integral count rates in the energy range of 7-2734 keV in several underground sites studied with the use of in situ HPGe spectrometry.

\begin{tabular}{|c|c|c|c|c|c|c|}
\hline Location & $\begin{array}{c}\text { Depth below } \\
\text { the Ground } \\
{[\mathrm{m}]}\end{array}$ & $\begin{array}{l}\text { Geological } \\
\text { Formation }\end{array}$ & $\begin{array}{c}\text { Count Rate } \\
\qquad\left[s^{-1}\right]\end{array}$ & Source & Detector Type & $\begin{array}{c}\text { Relative } \\
\text { Efficiency [\%] }\end{array}$ \\
\hline Boulby & 1100 & $\begin{array}{c}\text { halite } \\
\text { mudstone }\end{array}$ & $27.80 \pm 0.01$ & ILIAS [6] & HPGe p-type & 33 \\
\hline Gran Sasso & 1400 & $\begin{array}{l}\text { dolomitic } \\
\text { limestone }\end{array}$ & $47.84 \pm 0.02$ & ILIAS [6] & HPGe p-type & 33 \\
\hline Modane & 1200 & calcschist & $57.07 \pm 0.02$ & ILIAS [6] & HPGe p-type & 33 \\
\hline \multirow{4}{*}{$\begin{array}{l}\text { Polkowice- } \\
\text { Sieroszowice }\end{array}$} & 930 & salt & $1.95 \pm 0.02$ & ILIAS [6] & HPGe p-type & 30 \\
\hline & 930 & salt & $5.79 \pm 0.01$ & ISOTTA [6] & HPGe n-type & 40 \\
\hline & 930 & salt & $3.92 \pm 0.01$ & ISOTTA [6] & HPGe n-type & 25 \\
\hline & 1014.4 & anhydrite & $216.12 \pm 0.07$ & BSUIN & HPGe n-type & 40 \\
\hline Freiberg & 150 & gneiss & $702.53 \pm 0.06$ & BSUIN [12] & HPGe n-type & 40 \\
\hline Pyhäsalmi & 1450 & sulphide & $683.52 \pm 0.09$ & BSUIN [13] & HPGe n-type & 40 \\
\hline
\end{tabular}

The collective analysis of particular radionuclide contribution to apparent activity and effective dose rate is presented in Table 2 . Total effective dose rate in the studied location was equal to $0.008 \pm 0.001 \mu \mathrm{Sv} / \mathrm{h}(2.3 \pm 0.3 \mathrm{pSv} / \mathrm{s})$. The photon flux density is equal to $0.64 \pm 0.20 \mathrm{~cm}^{-2} \mathrm{~s}^{-1}$, whereas the spectrum continuum amounts to $4.94 \pm 0.77 \mathrm{~cm}^{-2} \mathrm{~s}^{-1}$. 
Table 2. Total apparent activity and effective dose rate (EDR) associated with each source of photon radiation recognized at the spectrum registered in situ. The relative contribution (\%) to each radionuclide to EDR is also shown.

\begin{tabular}{ccccccc}
\hline $\begin{array}{c}\text { Decay } \\
\text { Chain }\end{array}$ & Nuclide & $\begin{array}{c}\mathbf{A}_{\text {apparent }} \\
{\left[\mathbf{B q} / \mathbf{c m}^{2}\right]}\end{array}$ & $\begin{array}{c}\Delta \\
{\left[\mathbf{B q} / \mathbf{c m}^{2}\right]}\end{array}$ & $\begin{array}{c}\text { EDR } \\
{[\mathbf{p S v} / \mathbf{s}]}\end{array}$ & $\boldsymbol{\Delta}[\mathbf{p S v} / \mathbf{s}]$ & \% to EDR \\
\hline \multirow{5}{*}{ Uranium } & ${ }^{234} \mathrm{Th}$ & 0.095 & 0.087 & 0.002 & 0.0002 & 0.1 \\
& ${ }^{234 \mathrm{~m}} \mathrm{~Pa}$ & 0.255 & 0.017 & 0.007 & 0.001 & 0.3 \\
& ${ }^{226} \mathrm{Ra}$ & 0.177 & 0.004 & 0.003 & 0.0005 & 0.2 \\
& ${ }^{214} \mathrm{Bi}$ & 0.239 & 0.083 & 1.109 & 0.160 & 49.2 \\
& ${ }^{214} \mathrm{~Pb}$ & 0.205 & 0.096 & 0.093 & 0.013 & 4.1 \\
\hline \multirow{2}{*}{ Thorium } & ${ }^{228} \mathrm{Ac}$ & 0.063 & 0.041 & 0.091 & 0.013 & 4.0 \\
& ${ }^{208} \mathrm{Tl}$ & 0.019 & 0.007 & 0.271 & 0.039 & 12.0 \\
\hline \multirow{2}{*}{ None } & $40 \mathrm{~K}$ & 1.339 & 0.003 & 0.675 & 29.910 & 29.9 \\
& $\mathrm{X}-\mathrm{rays}$ & - & - & 0.005 & 0.001 & 0.2 \\
\hline
\end{tabular}

Photon flux densities for deep underground localizations are typically of the order of $1 \mathrm{~cm}^{-2} \mathrm{~s}^{-1}$ [2]. Data from 0.25 to $2.16 \mathrm{~cm}^{-2} \mathrm{~s}^{-1}$ are reported for existing underground laboratories [13]. In the previously studied localization in the salt layer $(930 \mathrm{~m}$ below the ground) of the Polkowice-Sieroszowice copper mine the value of $0.124 \pm 0.002 \mathrm{~cm}^{-2} \mathrm{~s}^{-1}$ was obtained for photon flux density, and $0.18 \pm 0.05 \mathrm{~cm}^{-2} \mathrm{~s}^{-1}$ for spectrum continuum [6].

The results of effective dose rate obtained with the same methodology and spectrometry system in other underground localizations show a higher radiation hazard at a depth of $1436 \mathrm{~m}$ within the volcanogenic sulphide deposit of Pyhäsalmi mine (Callio Lab, Finland) $0.158 \pm 0.029 \mu \mathrm{Sv} / \mathrm{h}$ [13], as well as at a depth of $150 \mathrm{~m}$ within the gneiss formation of the Reiche Zeche shaft of TUBAF (Germany) $-0.036 \pm 0.008 \mu \mathrm{Sv} / \mathrm{h}$ [12]. This suggests that the excavation within the anhydrite formation in the Polkowice-Sieroszowice copper mine is low-background localization with restricted radiation hazard. However, results published in 2010 [5] show an even lower gamma radiation dose within the salt excavation of the Polkowice-Sieroszowice mine, i.e., $0.002 \mu \mathrm{Sv} / \mathrm{h}$. Nevertheless, among non-salt localizations, the result of $8 \mathrm{nSv} / \mathrm{h}$ is about $2-3$ times lower than results obtained in the calcschist rock in LSM Modane-20 nSv / h [3], or in marble rock of Jinping - $23 \mathrm{nSv} / \mathrm{h}$ [14]. UNSCEAR reported the average effective dose of $0.41 \mathrm{mSv} /$ year $(47 \mathrm{nSv} / \mathrm{h})$ from indoor exposure to gamma radiation originating in construction materials [15].

The radioactivity level of thorium series radionuclides is lower than the radioactivity of uranium series radioisotopes, as shown in Table 2 . From the first one, only ${ }^{208} \mathrm{Tl}$ and ${ }^{228} \mathrm{Ac}$ are visible on the spectrum and peaks from ${ }^{212} \mathrm{Bi}$ and ${ }^{212} \mathrm{~Pb}$ are absent. A relatively high concentration of uranium series nuclides is seen in the spectrum by the intensity of ${ }^{214} \mathrm{Bi}$ lines, including escape peaks, summation peaks, and characteristic X-rays.

\subsection{The Ratio of $\mathrm{K}-40 / \mathrm{Bi}-214$}

The most visible on the registered spectrum of natural background radiation among the uranium series radioisotopes is ${ }^{214} \mathrm{Bi}$. Moreover, it is one of radon's daughters. Therefore its activity in the experimental site is connected with uranium concentration in the surrounding rock and radon generation. On the contrary, potassium ${ }^{40} \mathrm{~K}$ is only incorporated in the rock material in the underground location. Therefore, the ratio of count rates under the lines $1460.8 \mathrm{keV}\left({ }^{40} \mathrm{~K}\right)$ and $1764.5 \mathrm{keV}\left({ }^{214} \mathrm{Bi}\right)$ could characterize the radiation environment and distinguish between deep and shallow underground localizations.

${ }^{40} \mathrm{~K} /{ }^{214} \mathrm{Bi}$ cps ratio in the studied location equals 3.8, which is consistent with the results for deep localizations, according to suggestions made previously [12,13]. A summary of the ${ }^{40} \mathrm{~K} /{ }^{214} \mathrm{Bi}$ cps ratio for selected localizations is presented in Table 3. 
Table 3. The ratio of ${ }^{40} \mathrm{~K} /{ }^{214} \mathrm{Bi}(1460.8 \mathrm{keV} / 1764.5 \mathrm{keV})$ count rates as a function of depth below the ground.

\begin{tabular}{|c|c|c|c|}
\hline Place & ${ }^{40} \mathrm{~K} /{ }^{214} \mathrm{Bi}$ Cps ratio & $\begin{array}{l}\text { Detector Type } \\
\text { (Efficiency) }\end{array}$ & $\begin{array}{l}\text { Depth below the } \\
\text { Ground [m] }\end{array}$ \\
\hline $\begin{array}{c}\text { Institute of Physics, } \\
\text { University of Silesia, } \\
\text { Chorzów }\end{array}$ & 6.79 & HPGe, n-type (40\%) & 0 \\
\hline $\begin{array}{c}\text { Institute of Physics, } \\
\text { University of Silesia, } \\
\text { Katowice }\end{array}$ & 7.74 & HPGe, n-type (40\%) & 10 \\
\hline $\begin{array}{l}\text { Underground Laboratory } \\
\text { NCBJ, Łódź }\end{array}$ & 12.60 & HPGe, n-type (40\%) & 10 \\
\hline $\begin{array}{c}\text { Reiche Zeche shaft, } \\
\text { TUBAF, Freiberg }\end{array}$ & 14.47 & HPGe, n-type (40\%) & 150 \\
\hline $\begin{array}{l}\text { Polkowice-Sieroszowice } \\
\text { copper mine, salt cavern }\end{array}$ & $0.43-0.67$ & HPGe, n-type (40\%) & 930 \\
\hline $\begin{array}{l}\text { Polkowice- Sieroszowice } \\
\text { copper mine, anhydrite } \\
\text { excavation }\end{array}$ & 3.8 & HPGe, n-type (40\%) & 1014.4 \\
\hline $\begin{array}{l}\text { Boulby Underground } \\
\text { Laboratory of the } \\
\text { Institute of Underground } \\
\text { Science (IUS) }\end{array}$ & 4.06 & HPGe, n-type (32\%) & 1100 \\
\hline $\begin{array}{l}\text { Modane Underground } \\
\text { Laboratory (LSM) }\end{array}$ & 2.27 & HPGe, n-type (32\%) & 1200 \\
\hline $\begin{array}{l}\text { Gran Sasso National } \\
\text { Laboratory (LNGS) }\end{array}$ & 1.56 & HPGe, n-type (32\%) & 1400 \\
\hline $\begin{array}{c}\text { Pyhäsalmi mine, Callio } \\
\text { Lab, Finland }\end{array}$ & 8.01 & HPGe, n-type (40\%) & 1450 \\
\hline
\end{tabular}

\subsection{Radon Concentration in Air}

Radon ${ }^{222} \mathrm{Rn}$ concentration monitoring was conducted from 20 July to 22 July 2020, in the range of $0.6-20.0 \mathrm{~Bq} / \mathrm{m}^{3}$ with an average value of $6.6 \mathrm{~Bq} / \mathrm{m}^{3}$ and a median of $4.8 \mathrm{~Bq} / \mathrm{m}^{3}$. Relatively high uncertainties accompany such small values (Figure 4).

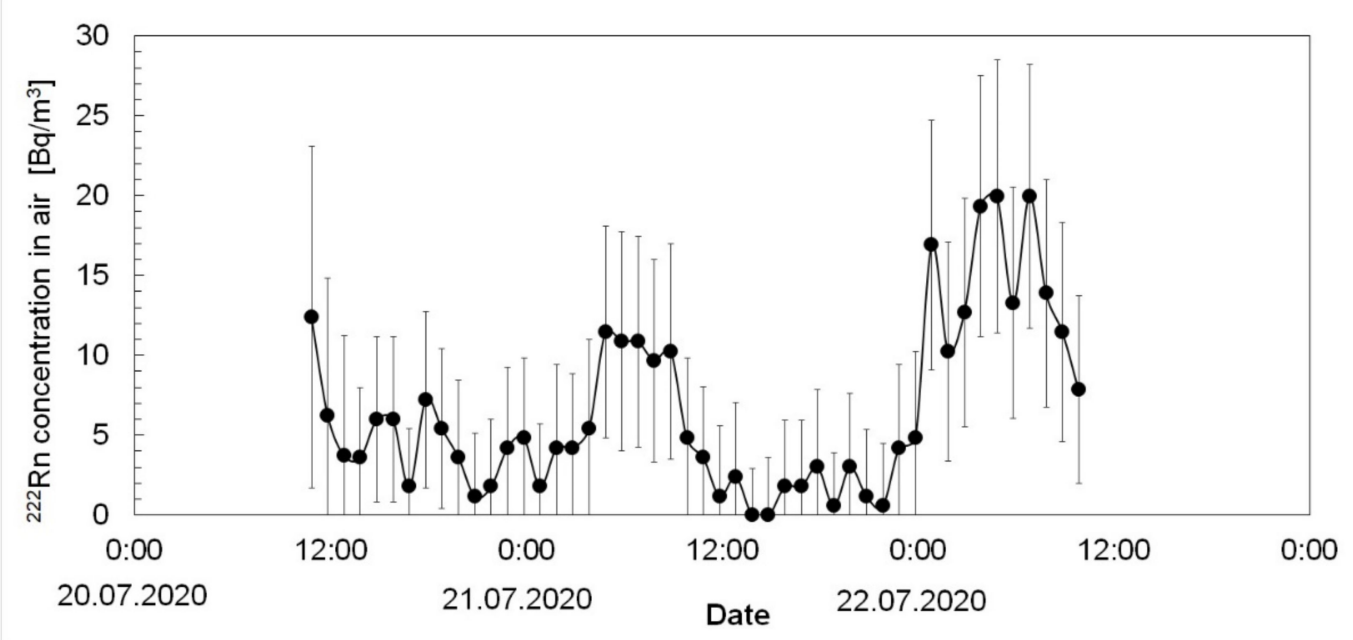

Figure 4. Time variation of radon concentration in air in excavation No. 3.

The radon concentration in the air in underground locations may vary by several orders of magnitude. The radon concentration is also influenced by humidity, temperature difference, and pressure between the surface and the underground site. The measured value 
of radon concentration in the air in the investigated location is relatively low compared to other European underground laboratories. The values of radon concentrations in the largest European underground laboratories are $3 \mathrm{~Bq} / \mathrm{m}^{3}, 15 \mathrm{~Bq} / \mathrm{m}^{3}$ [4], $80 \mathrm{~Bq} / \mathrm{m}^{3}$ [3], and $120 \mathrm{~Bq} / \mathrm{m}^{3}$ [4] for Boulby (UK), Modane (France), Canfrac (Spain), Gran Sasso (Italy) respectively with ventilation. An average value of $28.2 \mathrm{~Bq} / \mathrm{m}^{3}$ was measured in another location of the Polkowice-Sieroszowice mine in 2010 [5]. For comparison, the concentration of radon in the air measured near the SW-1 Mining shaft is over 30 times lower than the radon concentration measured at Callio Lab (Finland), which was $213.3 \mathrm{~Bq} / \mathrm{m}^{3}$ [13], and over 115 times lower than the concentration measured at the Reiche Zeche mine (Germany), which was $805.1 \mathrm{~Bq} / \mathrm{m}^{3}$ [12].

\subsection{Radioactivity Content in Rocks}

The radium, potassium, and uranium radioisotope concentrations in rock samples were measured using alpha and gamma spectroscopy. The analyzed samples are characterized by low activity concentrations of the analyzed isotopes. The ${ }^{226} \mathrm{Ra}$ concentrations ranged from $0.63 \pm 0.03 \mathrm{~Bq} / \mathrm{kg}$ to $21.1 \pm 0.7 \mathrm{~Bq} / \mathrm{kg}$ with the mean equal to $7.2 \mathrm{~Bq} / \mathrm{kg}$ and the median equal to $1.1 \mathrm{~Bq} / \mathrm{kg}$. The values of ${ }^{228} \mathrm{Ra}$ and ${ }^{40} \mathrm{~K}$ concentrations were in the range from $0.19 \pm 0.03 \mathrm{~Bq} / \mathrm{kg}$ to $0.60 \pm 0.10 \mathrm{~Bq} / \mathrm{kg}$ (mean: $0.3 \mathrm{~Bq} / \mathrm{kg}$, median: $0.2 \mathrm{~Bq} / \mathrm{kg}$ ) and from $6.1 \pm 0.2 \mathrm{~Bq} / \mathrm{kg}$ to $15.4 \pm 0.3 \mathrm{~Bq} / \mathrm{kg}$ (mean: $9.4 \mathrm{~Bq} / \mathrm{kg}$, median: $8.6 \mathrm{~Bq} / \mathrm{kg}$ ), respectively. The ${ }^{238} \mathrm{U}$ and ${ }^{234} \mathrm{U}$ concentrations were in the range: $0.82 \pm 0.08 \mathrm{~Bq} / \mathrm{kg}-24.37 \pm 0.73 \mathrm{~Bq} / \mathrm{kg}$ (mean: $8.8 \mathrm{~Bq} / \mathrm{kg}$, median: $1.6 \mathrm{~Bq} / \mathrm{kg}$ ) and $0.84 \pm 0.08 \mathrm{~Bq} / \mathrm{kg}-24.75 \pm 0.74 \mathrm{~Bq} / \mathrm{kg}$ (mean: $8.7 \mathrm{~Bq} / \mathrm{kg}$, median: $1.5 \mathrm{~Bq} / \mathrm{kg}$ ), respectively. The uranium content, calculated based on ${ }^{238} \mathrm{U}$ activity, ranged from $0.07 \pm 0.01 \mathrm{ppm}$ to $1.97 \pm 0.06 \mathrm{ppm}$. The analyzed samples showed a radioactive equilibrium between ${ }^{234} \mathrm{U}$ and ${ }^{238} \mathrm{U}$ isotopes. The mean and the median value of the ${ }^{234} \mathrm{U} /{ }^{238} \mathrm{U}$ activity ratios in the analyzed samples was equal to 1.0. All the samples exhibited lower values of ${ }^{226} \mathrm{Ra}$ compared to parent isotope ${ }^{238} \mathrm{U}$ and the ${ }^{226} \mathrm{Ra} /{ }^{238} \mathrm{U}$ activity ratio varied in a range from $0.68 \pm 0.04$ to $0.87 \pm 0.04$ with the median equal to 0.76 .

For comparison, the ${ }^{40} \mathrm{~K}$ concentration values in rock samples from Lab 2 of Callio Lab (Finland), for which similar measurements were performed, were in the range from $104 \pm 10 \mathrm{~Bq} / \mathrm{kg}$ to $1136 \pm 47 \mathrm{~Bq} / \mathrm{kg}$ [13] (concentration varied greatly depending on the place of sample collection). For the rock sample from the Reiche Zeche mine (Germany), the concentration of ${ }^{40} \mathrm{~K}$ was equal to $1049 \pm 17 \mathrm{~Bq} / \mathrm{kg}$ [12]. However, for the ${ }^{226} \mathrm{Ra}$ isotope, the concentration values in the rock samples from Lab 2 from Callio Lab ranged from $8.1 \pm 0.4$ to $188.2 \pm 5.1 \mathrm{~Bq} / \mathrm{kg}$ [13], while for the rock sample from the Reiche Zeche mine it was equal to $43.8 \pm 0.4 \mathrm{~Bq} / \mathrm{kg}$ [12]. In other European underground laboratories, the ${ }^{40} \mathrm{~K}$ values differ significantly. For example, in Boulby (UK), the measured concentration of ${ }^{40} \mathrm{~K}$ was equal to $11 \pm 1 \mathrm{~Bq} / \mathrm{kg}$ in halite, while in mudstone it was equal to $120 \pm 2 \mathrm{~Bq} / \mathrm{kg}$ [16]. In contrast, in San Grasso (Italy), $26 \pm 2 \mathrm{~Bq} / \mathrm{kg}$ was measured for dolomitic limestone [17], and in Modane (France), $213 \pm 30 \mathrm{~Bq} / \mathrm{kg}$ was measured in a rock sample [18]. On the other hand, the concentration of ${ }^{40} \mathrm{~K}$ isotope in an anhydrite sample collected from another location in the Polkowice-Sieroszowice mine in 2010 was lower than the detection limit [5]. Moreover, this sample showed a low concentration of ${ }^{238} \mathrm{U}$ isotope $(0.82 \pm 0.09 \mathrm{~Bq} / \mathrm{kg})$. Previous studies [5] of radionuclide content in anhydrite samples also exhibited higher values of daughter isotope ${ }^{230}$ Th than ${ }^{238} \mathrm{U}$.

\subsection{Qualitative Neutron Activation Analysis}

For a more in depth analysis of the site where in situ measurements were made, the rock sample's neutron activation from the location studied was carried out. This study aimed to assess the effect of neutron flux on the production of potential neutron-induced radionuclides. Radioisotopes could be activated if the neutron flux was more intense and could affect the gamma energy spectrum and contribute to radiation hazards at this location. A rock sample was irradiated with a neutron flux from a ${ }^{252} \mathrm{Cf}$ source for 45 days. 
Immediately after the neutron activation of the rock sample, the gamma radiation spectrum was registered using the HPGe detector described in Section 2.3. Several series of measurements were performed for the qualitative analysis of trace elements. First, short measurements were made to record spectral lines emitted by short-lived isotopes, while longer measurements made it possible to detect long-lived radionuclides. Such analysis allows short- and long-lived radioisotopes to be registered with a different quantum efficiency of spectral lines and to avoid overlapping spectral lines during more extended measurements by the spectral continuum from natural background radiation.

In the activated sample, two radioisotopes were recorded on the gamma radiation spectrum, formed on the rock's impurities due to the reaction $(n, \gamma)$. They were ${ }^{24} \mathrm{Na}$ $(1368.6 \mathrm{keV}(100 \%))$ and ${ }^{56} \mathrm{Mn}(846.8 \mathrm{keV}(98.9 \%))$ [19]. Based on the activated rock sample's recorded spectra, it was estimated that the count rate ratio of ${ }^{24} \mathrm{Na} /{ }^{56} \mathrm{Mn}$ was 2 to 4 , depending on the spectral counting statistics. Considering the differences in the half-lives of both isotopes, this suggests a much higher sodium concentration in the activated rock than manganese concentration. Sodium and manganese have one stable isotope each: ${ }^{23} \mathrm{Na}$ and ${ }^{55} \mathrm{Mn}$ and are characterized by a high thermal neutron capture cross-section [19] of $0.530 \mathrm{~b}$ and $13.3 \mathrm{~b}$, respectively. This is important from the underground site's point of view because the neutron thermal flux is the main component of the neutron flux deep into the location. Therefore, activated radionuclides could increase the radiation background there.

\subsection{Neutron Flux Results}

Data was collected for approximately four days (20-23 July 2020). We used two kinds of helium detectors: 2 inches in diameter, $50 \mathrm{~cm}$ long tubes with $2 \mathrm{~atm}$ of ${ }^{3} \mathrm{He}, 0.5 \mathrm{~atm}$ of Argon, some CO gas, and 25-micrometer wires made by Centronic in 2008, and old thinner (1 inch), $50 \mathrm{~cm}$ long tubes with $4 \mathrm{~atm}$ of ${ }^{3} \mathrm{He}$ and Krypton stopping gas produced by ZDAJ in 60ties. Centronic detectors were optimized to record most of the neutron counts in energies close to $764 \mathrm{keV}(60 \%$ on average), whereas ZDAJ counters have on average $37 \%$ neutrons in the maximum energy peak. Accumulation of most neutrons in a large peak is essential for measuring a low neutron flux environment (to dominate internal alpha particle background). Results of the measurements are presented in Table 4. Assuming that the neutron count rate is constant in time, one can fit the data and find the average rate of neutron counts per hour per single counter. The measurement described here amounted to $2.8 \pm 0.2$ counts $/ \mathrm{h}$ for Centronic counters and $1.9 \pm 0.2$ counts $/ \mathrm{h}$ for ZDAJ counters.

Table 4. The number of neutrons collected by single Centronic and ZDAJ counters.

\begin{tabular}{ccc}
\hline Number & Centronic & ZDAJ \\
\hline 1 & 101 & - \\
2 & 79 & 62 \\
3 & 103 & 49 \\
4 & 101 & 44 \\
\hline average & 96.0 & 51.7 \\
sigma & $11.4(12 \%)$ & $9.3(18 \%)$ \\
\hline
\end{tabular}

The measurement results were compared with the Monte Carlo simulation, assuming that the measurement setup was isotropically illuminated by thermal neutrons. As a result of the comparison, the neutron flux at the measurement site can be determined. It is $1.9 \pm 0.2 \times 10^{-6} \mathrm{~cm}^{-2} \mathrm{~s}^{-1}$ for Centronic counters and $2.2 \pm 0.4 \times 10^{-6} \mathrm{~cm}^{-2} \mathrm{~s}^{-1}$ for ZDAJ counters.

The obtained results are consistent within the limits of the statistical error. Therefore, their weighted average is the final result. Therefore, the thermal neutron flux in the Polkowice-Sieroszowice mine is: $2.0 \pm 0.2 \times 10^{-6} \mathrm{~cm}^{-2} \mathrm{~s}^{-1}$.

This result, comparing with the results of measurements carried out in other locations using a similar measurement set, is presented in Table 5. 
Table 5. Comparison of thermal neutron flux measurement in different European underground locations.

\begin{tabular}{cc}
\hline Location & Flux of Thermal Neutrons $\left(\times \mathbf{1 0}^{-\mathbf{6}} \mathbf{~ m}^{-\mathbf{2}} \mathbf{~ s}^{-\mathbf{1}}\right)$ \\
\hline Polkowice-Sieroszowice, (Poland) & $2.0 \pm 0.2$ \\
Gran Sasso, (Italy) & $0.56 \pm 0.22[20]$ \\
Slanic Prahova, (Romania) & $0.12 \pm 0.05[20]$ \\
Freiberg, (Germany) & $3.12 \pm 0.10[12]$ \\
Pyhäsalmi; Lab2 (Finland) & $17.30 \pm 0.10[13]$ \\
\hline
\end{tabular}

The neutron flux in the Polkowice-Sieroszowice mine turns out to be relatively low. Lower background conditions are only found in the Slanic salt mine (Prahowa, Romania), where the salt deposit is almost entirely devoid of natural radioactivity, and in the underground laboratory in the tunnel under the Gran Sasso mountains (LNGS Gran Sasso, Abruzzo, Italy) where neutrons are probably absorbed by the concrete tunnel cover, a meter thick and moist. Note that the excavation No 3 in the Polkowice-Sieroszowice mine is dry and devoid of a thick lining.

\section{Conclusions}

Based on the performed measurements, it can be concluded that the natural background radiation observed in the Polkowice-Sieroszowice mine is suitable for setting up research facilities related to physical measurements. From the analyses performed within our research it turned out that the best underground location for low radioactivity-level measurements is the P1 salt chamber located in the Polkowice-Sieroszowice mine.

Author Contributions: Conceptualization, J.K., K.P.-G., K.S., A.W.-Ł.; methodology, J.K., K.P.-G., K.S., A.W.-Ł., K.J., J.S., M.K., K.F., S.G.; formal analysis, K.S., A.W.-Ł.; investigation, J.K., K.P.-G., A.W.-Ł., K.S., K.J., J.S., M.P.; resources, P.T., J.O., W.M.; writing—original draft preparation, K.P.-G., A.W.-Ł., K.S., K.J. and K.F.; writing-review and editing, J.K., K.F., S.G., J.S.; visualization, J.K.; supervision, J.K. All authors have read and agreed to the published version of the manuscript.

Funding: This research was funded by Interreg Baltic Sea Region, grant number: \#R037 Baltic Sea Underground Innovation Network (BSUIN) and \#X010 Empowering Underground Laboratories Network Usage (EUL), and the Research Excellence Initiative of the University of Silesia in Katowice.

Institutional Review Board Statement: Not applicable.

Informed Consent Statement: Not applicable.

Data Availability Statement: The data presented in this study are available on request from the corresponding author.

Conflicts of Interest: The authors declare no conflict of interest.

\section{References}

1. Bettini, A. The world underground scientific facilities. A Compendium. arXiv 2007, arXiv:0712.1051.

2. Bettini, A. The world deep underground laboratories. Eur. Phys. J. Plus 2012, 127, 114. [CrossRef]

3. Coccia, E. Underground laboratories: Cosmic silence, loud science. J. Phys. Conf. Ser. 2010, 203, 012023. [CrossRef]

4. Pandola, L. Overview of the European underground facilities. AIP Conf. Proc. 2011, 1338, 12. [CrossRef]

5. Kisiel, J.; Budzanowski, M.; Dorda, J.; Kozak, K.; Mazur, J.; Mietelski, J.W.; Puchalska, M.; Tomankiewicz, E.; Zalewska, A. Measurements of natural radioactivity in the salt cavern of the Polkowice-Sieroszowice copper mine. Acta Phys. Pol. B 2010, 41, 1813-1819.

6. Polaczek-Grelik, K.; Kisiel, J.; Walencik-Łata, A.; Mietelski, J.W.; Janowski, P.; Harańczyk, M.; Jurkowski, J.; Zalewska, A.; Kobziński, J.; Markowski, P.; et al. Lead shielding efficiency from the gamma background measurements in the salt cavern of the Polkowice-Sieroszowice copper mine. J. Radioanal. Nucl. Chem. 2015, 308, 773-780. [CrossRef] [PubMed]

7. Mietelski, J.W.; Tomankiewicz, E.; Grabowska, S. Report IFJ 1960/C; IFJ: Kraków, Poland, 2005. (In Polish)

8. Zalewska, A.; Pytel, W.; Chorowski, M.; Cygan, S.; Hanzel, S.; Januszewska, K.; Jaroń, L.; Kisiel, J.; Lankof, L.; Markiewicz, A.; et al. Laguna in Polkowice-Sieroszowice Mine in Poland. Acta. Phys. Pol. B 2010, 41, 1803-1820.

9. Kisiel, J.; Budzanowski, M.; Chorowski, M.; Cygan, S.; Dorda, J.; Hanzel, S.; Harańczyk, M.; Horoszczak, L.; Januszewska, K.; Jaroń, L.; et al. SUNLAB—The Project of a Polish Underground Laboratory. AIP Conf. Proc. 2010, 1304, 326. [CrossRef] 
10. Autiero, D.; Aysto, J.; Badertscher, A.; Bezrukov, L.; Bouchez, J.; Bueno, A.; Busto, J.; Campagne, J.-E.; Cavata, C.; Chaussard, L.; et al. Large underground, liquid based detectors for astro-particle physics in Europe: Scientific case and prospects. Cosm. Astropart. Phys. 2007, 2007, 011. [CrossRef]

11. ICRP Publication 116; Ann. ICRP 40(2-5); ICRP: Stockholm, Sweden, 2010.

12. Polaczek-Grelik, K.; Walencik-Łata, A.; Szkliniarz, K.; Kisiel, J.; Jędrzejczak, K.; Szabelski, J.; Mueller, T.; Schreiter, F.; Djakonow, A.; Lewandowski, R.; et al. Characterization of the radiation environment at TU Bergakademie in Freiberg, Saxony, Germany. Nucl. Instrum. Methods Phys. Res. A 2019, 946, 162652. [CrossRef]

13. Polaczek-Grelik, K.; Walencik-Łata, A.; Szkliniarz, K.; Kisiel, J.; Jedrzejczak, K.; Szabelski, J.; Kasztelan, M.; Joutsenvaara, J.; Puputti, H.J.; Holma, M.; et al. Natural background radiation at Lab 2 of Callio Lab, Pyhäsalmi mine in Finland. Nucl. Instrum. Methods Phys. Res. A 2020, 969, 164015. [CrossRef]

14. Cheng, J.P.; Kang, K.-J.; Li, J.-M.; Li, J.; Li, Y.-J.; Yue, Q.; Zeng, Z.; Chen, Y.-H.; Wu, S.-Y.; Ji, X.-D.; et al. The China Jinping National Laboratory and its early science. Annu. Rev. Nucl. Part. Sci. 2017, 67, 231-251. [CrossRef]

15. UNSCEAR. Sources, Effects and Risks of Ionizing Radiation; UNSCEAR 2016 Report; UNSCEAR: New York, NY, USA, 2017.

16. Malczewski, D.; Kisiel, J.; Dorda, J. Gamma background measurements in the Boulby Underground Laboratory. J. Radioanal. Nucl. Chem. 2013, 298, 1483-1489. [CrossRef] [PubMed]

17. Malczewski, D.; Kisiel, J.; Dorda, J. Gamma background measurements in the Gran Sasso National Laboratory. J. Radioanal. Nucl. Chem. 2013, 295, 749-754. [CrossRef] [PubMed]

18. Malczewski, D.; Kisiel, J.; Dorda, J. Gamma background measurements in the Laboratoire Souterrain de Modane. J. Radioanal. Nucl. Chem. 2012, 292, 751-756. [CrossRef] [PubMed]

19. Firestone, R.B.; Shirley, V.S. Tables of Isotopes; John Wiley \& Sons Inc.: Hoboken, NJ, USA, 1996.

20. Dębicki, Z.; Jędrzejczak, K.; Kaczmarczyk, J.; Kasztelan, M.; Lewandowski, R.; Orzechowski, J.; Szabelski, J.; Szeptycka, M.; Tokarski, P. Neutron flux measurements in the Gran Sasso national laboratory and in the Slanic Prahova Salt Mine. Nucl. Instrum. Methods Phys. Res. A 2018, 910, 133-138. [CrossRef] 